\title{
Analysis of Relationship between Bodies and Signs
}

\author{
Tu Yan \\ Chongqing Three Gorges College \\ Tuyan1630@163.com
}

KeyWords: Body; Signs; Perfomativity; Agency; Construction

\begin{abstract}
As the development of semiotic, the word "body" as become the key term in the field of modern philosophy. This paper put emphasis on the relationship between bodies and signs, pointing out body falls in conflict between hiddenness and prominent image by virtue of signs, which can be stated by "the problem of agency". Butler intends to solve this problem within discourse semiotics by resorting to theory of performativity. We are, therefore, forced to reflect the flesh body in a next context, and even to explore the problems beyond the frame of Western culture and philosophical thought.
\end{abstract}

\section{Introduction}

Supposed conversion is a reversed part of movement, the terms of "body conversion" and "semiotic conversion" not only demonstrate the core relationship between the terms and philosophy, but also imply the reason for its renown that is restate the hidden history of repression. "Body" and "sign" start to get rid of dualistic construct between psychology and body, signified and signifier. However due to the combination of body and sign, the difficulty consisting in body has taken on in unprecedented form including semiotic failure relevant to agency. On the contrary, the intrinsic requirement of agency reflects one reversed side of semiotic body, constructing other reversed part of body movement.

\section{Origin of Body Construction}

In terms of traditional western philosophy, people attempt to recognize their own identity by decorporealize instead of body. Descartes explored cogito that the obvious fact I have a body has been dodged. [1] Sociologist Turner has remarked it is more accurate to regard the absence of body as ignorance about body. Foucault is deemed as the most outstanding sociologists who research the body in Discipline and punishment. Foucault explores the historical events from parchment manuscript by means of genealogy, describing how Damiens was tortured physically in detail. The brutal scene covers the subject that Foucault intends to analyze that is the influence of power on body. The punishment on Damiens typically represents how traditional power operates, different from the way that modern power operates. The way that the modern power resorts to is moderate, moral and scientific. From the perspective of punishment, people are reluctant to contact body directly; in addition, physical pain is no longer the aim of punishment, body is just a tool of media for operation of power. [2] Accordingly, the people in charge of punishment consists of guard, doctor, clergymen, psychiatrist and so on instead of the authority represented by executioner, Thus the focus of modern power is not placed on the compulsion and repression consisting in modern power, but on the internalization of the power, so that subjects are transformed to espoused the operation of power.

The shift of way that power operates described by Foucault illustrates the shift of body. From this perspective, body turns to be a tame one subject to power, bound to get involved into 
some political domestic. The constructed body is operated by power bringing social code, which provides a theory for retrospective study; consequently we can decode the way of power operation by analyzing the political body, which is declared as political anatomy by Foucault. This kind of research way comprises the important standard for modern thinking through the body.

Body, carrying rich social culture, has become an important issue of cultural study as a cultural text. Inscribed into body; the development of events shows the tendency of history, in other word, history is the mere body leading to change. History always inscribes change into body according to ancestry, which is called as the way of genealogy.

Body described by Foucault is a one constructed by society and inscribed by culture. Body is the produced by discourse practice, the operation of power equals to the production of discourse carrying and producing power. Discourse originates from semi logy, while the socialization of body should depend on signification of sign.

\section{Sexual Identity}

Feminism prefers to struggle for social right by resorting to body construction, as a way of social criticism. Consequently, feminism political criticism shows a displacement from physical body to discourse body. The view on body based on discourse construction assists feminism to break the chain of physiological essentialism. From the perspective of post- feminism, it is necessary to adopt semiotic construction so as to shake off physiological logic about sex. That is to say, traditionally the description about physical body is restrained to discourse construction. "Some concepts such as physiological sex in essence, masculinity and femininity are constructed as an integral part of strategy.'[3] Foucault asserted these strategies are only part of operation of power, serving the male's right.

Butler declared that the body is a place where discourse and power system are inscribed. The change of society and operation of power are bound to leave a trail on the surface of body. Therefore, the surface of body is a text full of signs, carrying the trail of social development and power operation. These tracks are the origin of body. Foucault points out there is no body prior to law nor sex exclusive to power, but there is a doubt whether there is a body exclusive to construction and dynastic position resistant to culture. [4] Literally, inscription refers to writing on an empty place as a loaded body similar to tabula rasa. In other word, body is supposed to be an empty place without meaning and culture to be inscribed. Supposed construction turned out to be inscription described by Foucault, there is bound to be a body prior to inscription as a basis for supporting a steady premise.

As mentioned above, Foucault described the scene of torture vividly. Traditional physical punishment means torture being practiced on body. In modern society, punishment evolved to be a gentle way of control on morality. However there is also an equivalent loaded body subject to this gentle way of control. To some extent, body is regarded as a tool of media. Foucault still falls into dilemma between physical body and social body. A to Butler, the materiality of body has been already regulated by social situation. Set sexy identity as an example, there is no body without being sexualized. It means there is no natural body prior to discourse. Therefore, Butler tells the difference between performance and performativity. From the respect of performance, in a makeup ball, it is comprehensible to people to see gender role doesn't match physical sex and grasp there is another behavior subject after such a behavior in this special scene. But suppose there is person wearing a disguise on a bus, it is difficult to take his behavior as performance. Since in our daily life, we just identify their sexy identity from their appearance and disposition as a subject determined by characters. As to performativity, there is no physiological body and no such a behavior agency. 
Since agency is just the institution, discourse and result of practice, which is also apt for body. Butler can take attack on masculinity resorting to discourse construction.

However, supposed Butler excluded body of agent and subject of arrangement. How is positive meaning of sexual performativity represented? Presuming all the discourse is constructed, how to choose the direct ad type of construction? As to Foucault, body is loaded with trail of operation of power passively. It is the object surround by soul; it means soul deems the body as a stone tablet carved with its own achievement; consequently body remains silent imposed by culture.

\section{Agency of Construction}

There is a wrong view about performativity that is the effective expression by applying language according to personal will.[5]For example, how to gain the sex identity, just like you open the wardrobe full of various dress implying the gathering of various sexy identity, you choose a favorite one to put on or take off at your disposal. According to Butler, it is unnecessary to identify ego prior to signification in order to answer the questions relevant to agency. For the ego is the result of construction not the reason. Compared with dressing, performativity intends to eliminate sort of undertaker of body in the process of performance. "Performance presets a subject, but performativtiy shows doubt about the subject." [6] What's more, performativity concerning to political morals firstly consist in crumbling subject.

There exists no independent subject, accordingly the physical body with strong emotion and will consisting in the subject will be eliminated too. The fallacy of agency in subjectivity is subject is only an agency based on compulsory discourse; meanwhile these discourses arouse our agency. It is not supposed to seek for the agency of discourse construction from respect of physical body. Originally, the social construction represents a sort of symbolic agency. In a word, the agency of construction is attributed to symbol on condition that the signification of symbol generate automatically instead of depending on signifier, placing emphasis on ability of practice and construction of symbol

\section{Summary}

In conclusion, the discourse represented two respects. On one hand, discourse constructs subject and body, on the other hand, discourse provides wide space of agency for subject. However the agency is not wholly represented in discourse symbol. The key point for approval of agency is the repetition of symbol. In addition, the materialism of body is not just the border of discourse signification; Semiotic constructionist adopts the strategy that signified should be melted into signifier, which demonstrates the significance of embodiment.

\section{References}

[1] Drew Leder, the Absent Body, The University of Chicago Press, Chicago, 1990.

[2] Michel Foucault, The Foucault Reader, ed. , Paul Rabinow, Pamtheon Book, New York, 1984.

[3] Judith Butler, Gender Trouble: Feminism and the Subversion of Identity, Routledge, New York \& London, 1999.

[4] Judith Butler, Foucault and the Paradox of Bodily Inscriptions, The journal of Philosophy, 98 (1989) 602.

[5] Judith Butler, Bodies that matter: On the Discursive Limits of "sex", Routledge, London \& New York, 2011.

[6] Judith Butler, Gender as Performance: An Interview with Judith Butler, Radical Philosophy: A Journal of Socialist and Feminist Philosophy, 67(2001)32 